\title{
Study on Mathematical Culture Application Value Research under the Public Mathematics Education
}

\author{
Guo-cheng LI \\ Linyi University, Feixian Campus, Feixian, Shandong, China \\ lyulgc@126.com
}

Keywords: Public mathematics, Mathematics education, Mathematical culture, Thinking quality.

\begin{abstract}
Mathematics is a culture for human. The mathematical content, concepts, solutions and linguistics are the important parts of the modern civilization. It is aimed at improving the quality of the students, especially in enhancement of national quality, which is the final goal in Mathematics Education. Therefore, the study on the characteristics and nature of mathematical culture education is an urgent subject in mathematics education. This paper is to further discuss the mathematical culture value from the parts of its origin and characteristics, culture and thinking quality as well as the revolution of the education concept.
\end{abstract}

\section{Introduction}

Mathematics is a culture for human. The mathematical content, concepts, solutions and linguistics are the important parts of the modern civilization. However, in what respects do the Mathematical Culture embodied? How to deal with the mathematical content, concepts, solutions and linguistics? What roles they can play in mathematics? All of these questions are worthy to discuss. This paper proposed the topics in these problems.

\section{To Communicate Two opposite Cultures}

In the late 1950s, the Britain scholar C. P. Snow (1905-1980) published his famous paper Two Cultures and the Scientific Revolution. He believes that in today's society, people engaged in research on any subject would have the possibilities to ignore the other disciplines, if not, they are often poorly understood and the communication between each other is extremely difficult. There are two contradictory cultures in today's society, the one is the culture of science, the other is the culture of humanity. And there is a gap between these two cultures. This kind of culture division is danger to society and it also a loss of the society [1]. In order to solve the current situation of the disconnect between science and humanity, people are trying to explore the way to integrate these two cultures and to coordinate the development, through which our society and people can be coordinated in an orderly, healthy and civilized development. Mathematics occupied a special position between science and humanity, which has the potential to play a positive role in the integration of science and humanity.

\section{To Combine the Two Methods of Thinking}

Lots of scholars divided the ways of human thinking into two types, the one is the western thinking system, which is based on axiom, the other is the eastern thinking system, which is based on the modular method originated in Zhouyi [2]. There are still 
many scholars who believe that the important reason why in ancient China, people had a brilliant achievement in science and technology with it is far behind in modern time is people did not establish the axiomatic thinking system. While in my point of view, the modular thinking method in east maintains the paralleled significance with the western axiomatization thinking method [3]. They were all possessed an influential position in human's cognition in truth and it will always be in the following decades. They are the supplement for each other instead of a gap between them or the difference of advantages and disadvantages. Mathematical culture can explain this problem. It is the various similarities in the essence of the axiomatic method and modular method, they cannot be apart from each other.

Firstly, the correctness of the axiomatic method is based on two pillars, the one its nature of truth, the other is the validity of the logical method. The Original of Euclid is the model of this kind of thinking system. While the birth of noneucildean geometry has shaken its first pillar. It makes people realized that the world is diverse and the truth is relative, even if the axiom which seems extremely simple and self-evidenced also has its relativity. Again the emergence of "Set the Theoretical Paradox" has shaken its another pillar. So the axiomatic method sometimes can not afford to modular method with the overall consideration in axiom system, which is similar to the modular thinking method.

Secondly, the axiomatic method requires the axiom systems with more consistency and less contradictions, otherwise, it will end with absurd conclusions. Then, how to determine if the axiom systems have their nature of contradictions? It will be tested through practical model. As of today, with informatization, the starting point in scientific theories is equals to establish a kind of mathematical model. Through this way, people combined the axiomatic method with modular method.

Thirdly, it is no use of the deductive reasoning methods in axiomatic method, if it didn't come up with new conclusion. Then, how to come up with the new conclusion? Human's history shows that in most circumstances, it should adopt from the modular method. They suppose the new conclusions through ways of induction, analogy, etc in the existing mode, then testify their new conclusion in axiomatic method.

Fourthly, Axiomatic approach launched conclusions in closure. The limitations of axiomatic lifts people to find a way from the relatively on-limits modular thinking. Conversely, the modular method cannot be apart from axiomatic either. In a sense, the starting point that modular method depends is also the axiomatic method, which is a huge system. It is not the simplest system. Although in general, the reasoning method of modular thinking is not in deductive, it belongs to the deductive method in many parts and details. There's no difference with axiomatic method.

\section{To Renew the Idea of Mathematics Education}

Mathematics is a science of thinking, the conclusion is related with the whole world. It is regardless of the differences in nation or region. The axiomatic method, which is represented by Original, has made the great contributions to the mathematics development. Chinese ancient mathematics is focus on its procedure and model, it also made important contributions to the mathematics development. The calculus has been invented in western countries, while people processed its mechanical proving in China. Through this path, people recognized the value of the eastern mathematics. Indian mathematician Ramanujan often mere intuition can get many correct conclusions. Indian mathematician Ramanujan often get many correct conclusions merely through his perceptual intuition. All of these phenomenon is the reflex of 
mathematical culture, which should be paid with more attention in mathematics teaching materials.

Primary and middle school mathematics curriculum mainly contains two aspects: teaching geometry in a logical manner and introducing algebra in a non-logical manner. How to deal with the relations between geometry and algebra is an important part in the mathematics education reform. The educational goal in middle school algebra is mainly emphasize on the cultivation of the axiomatic method. It is not only the object in related with the mathematics education, but the in cultural quality education. People may not familiar with the majorities of geometry theorem, but they should be familiar with the axiomatic thinking method. Thus the specific geometry content in middle school textbook can be reduced properly, but the reasoning and thinking method should not be cut. For a long time, the mathematics teaching method is mainly divided in two types: the one is focus on the class, which is made up of the basic procedures in introduction of the definition and theorem, demonstration of the correctness for definition or theorem and exploration in related inferences. The other is focus on the exercises, which is conducted through examples demonstration, rules conclusion and intensive training in exercises. The former educational method is the application in axiomatic thinking method, the latter one is the reflection in modular thinking. Although there are many new teaching theories in Mathematics, the improvements or changes in teaching method is no more than these two types.

To renew the teaching idea in Mathematics, one should pay more attention in mathematical culture. It is necessary to study on the mathematical culture background to firm the new teaching idea. For instance, the popular situational teaching method, which encourages students to come up with the mathematical problems from daily life, and firm the conclusion. However, if the students establish the situation blindly for situational teaching, it will consume lots of time as well as weak the self study and abstract thinking abilities in maths study. The Chinese ancient mathematicians who emphasized on humanistic pragmatism may be one of the factors which lead to China's modern mathematics fell behind.

Mathematical culture indicates that those questions just like "Seven Bridge Problem", "36 Officers question", are all built up with a new mathematical branch in the procedure of solving problems [4]. But to build up the noneuclidean geometry and to discover the hundreds of big prime numbers are not in related with practical problems in the very beginning, while they all well applied into today's routine.

\section{To Cultivate the Student's thinking Quality}

Mathematics education can not only improve the quality of people's thinking, but also improve the quality of people's minds. To a great content, Mathematics education is a kind of cultural quality education.

In Chinese ancient time mathematics is one of the Six Arts (including music, archery, mathematics, ritual, chariot-riding and calligraphy), it is one part of culture quality education [5]. Ancient Greek scholar Plato hanged a door plate in his lyceum, which indicated people do not understand geometry should not access. The courses in his lyceum are not in any direct contact with geometry. In fact, Plato's lyceum is mainly instructed courses about sociology, political science and ethics. While he believed that the student without mathematical training can hardly doing well in courses he provided in his lyceum. It is said that the British lawyers should learn lots of advanced mathematics knowledge in university. It is not because of Mathematics knowledge will be in great help with their future career, but people and scholars 
believe that it is only through the mathematical training, those future lawyers will possess the good qualities such as perseverance, honesty and integrity. So that they can carefully clarify the context of the cases and seize the key issues when they met those complex cases.

Under the influence of the mathematical culture, many of the mathematicians are both outstanding in mathematical achievements and ideological quality. In order to defend for his country, Mathematician Archimedes contributed all his knowledge in science and technologies to help the army beat off the enemy of the invasion. Due to the strength disparity, the ancient city of Syracuse, in which Archimedes lived had been breached by the enemy. Even at that day, the 75-year-old mathematician was still in studying geometric figure, then sacrificed under the knife of the enemy. For the sake of persistent pursuit of career, philosophers sacrificed their lives. Mathematician Euler unparalleled achievements have been made not only in the field of mathematics, but in astronomy, maritime navigation, architecture and other science field. Due to excessive hard working and illness, he was blind in 59 years old. In his 64, all his book collections and research results have been burned into ashes in a fire disaster. While Euler did not been defeated by all of these misfortune. After 17 years of his blindness, he published more than 400 monographs by dictation under the help of his daughter. The quantity of the monographs is more than half of his life's work. Russian mathematician Lobachevsky established the non-Euclidean geometry theory. Because of his theory has violated the two thousand years of tradition, not only shook the inviolable authority of Euclidean geometry, but astonished the scholars in philosophy. It changed the way people recognized the truth, and even violated their "common sense". Thus, after his theory has been published, Lobachevsky have been hunted, doubted, contempt. The archbishop announced that his theory is "heterodox"; the medias criticized him as "nuts" in their publications; the academic authority said that his theory is "the absurdity of pseudoscience". While Lobachevsky is fearless, he appeared to be a scientist who bravely pursue in truth. There are many famous scholars who have had fallen into extreme poverty, while they insist on mathematics study. For example, the French mathematician Abel, Indian mathematician Ramanujan, Chinese mathematician Li Ye in Yuan dynasty and the contemporary mathematician Hua Luogeng. There are too many respectable and admirable mathematicians and their epic stories, which have provide the rich materials to cultivate the students' thinking quality in mathematics education.

\section{Conclusions}

Through the analysis above, we can figure out that the competency-based education and culture-based one are all played an influential role in mathematics education, while the emphasis points are different. In order to make full use of mathematics education in national quality improvement, the mathematics education should be comprehensive in knowledge, skills training as well as culture cultivation. It should be adjusted with their objects, and also with the different levels, so that the value of mathematics education will be demonstrated.

\section{Acknowledgment}

The author wishes to express his sincere thanks to the editor and the anonymous referees for their valuable suggestions and helpful comments which could improve the presentation of the paper. 


\section{Reference}

[1] Wan Yuan, Zhang Xiaorou, Chen Jianye, The Penetration of Mathematical Culture Thinking in College Mathematics Teaching [M]. Journal of Technology College Education, 2008 (1): pp.90-92.

[2] Han Hua, Wang Weihua, Study on Introduce in Mathematics Culture in College Mathematics Teaching[M]. China University Teaching, 2007, (12): pp. 21-23.

[3] Li Pingheng, Introduce to Mathematics Culture and Mathematics Teaching[J].Journal of Changchun Education Institution ,2008, (02) :pp.74-75.

[4] Feng Guangting, Mathematical Cultural View and the Characteristics of Mathematical Culture[J]. Wu Junming, The Science Education Article Collects, 2008, (2):pp.185-186.

[5] Liao Zhengqi, He Qingbi, The Influence of Confucian Thought in Mathematical Culture and Education Value[J].Journal of Chongqing University of Arts and Sciences, 2008, (3): pp.74-77.

[6 ] Han Qun, Teaching Research of Vocational College Student in Consciousness in Mathematics Application[J]. Shandong Normal University, 2005. 